\title{
An Overview of the Energy Sector in Malawi
}

\author{
Gregory E. T. Gamula ${ }^{1}$, Liu Hui ${ }^{1}$, Wuyuan Peng ${ }^{2 *}$ \\ ${ }^{1}$ School of Environmental Studies, China University of Geosciences, Wuhan, China \\ ${ }^{2}$ School of Economics and Management, China University of Geosciences, Wuhan, China \\ Email: *pengwy@yahoo.cn
}

Received November 5, 2012; revised December 10, 2012; accepted December 20, 2012

\begin{abstract}
This paper presents the status of the energy sector in Malawi which is not effectively contributing to the national economic development because it is unreliable and insufficient hence not able to meet the energy demand. About $83 \%$ of Malawi's population live in rural areas and rely on fuel wood for energy supply. High reliance on biomass has had negative environmental impacts through indoor pollution, deforestation, soil erosion leading to high soil sediment loads to water bodies resulting in poor water quality in rivers and lakes. Electricity supply is much less than demand resulting in deficient and unreliable supply. Malawi is endowed with a number of renewable energy resources yet utilization of these resources is still a major challenge. Little progress has been made in improving the energy supply situation due to a number of reasons, main ones being poverty, lack of political will and wrong approaches in addressing the energy problem. Most current approaches aim at improving the current situation but our opinion would be to develop new strategies to shift the energy situation from its present condition to the desired status. The paper starts with an introduction, then status of the energy sector, then goes on to discuss energy development efforts according to sectors and finally gives a conclusion.
\end{abstract}

Keywords: Energy Supply; Energy Development; Energy Resources; Electrical Energy

\section{Introduction}

Malawi is a land locked country located in Southern Africa, between latitudes $9^{\circ} 22^{\prime} \mathrm{S}$ and $17^{\circ} 3^{\prime} \mathrm{S}$ and longitudes $33^{\circ} 40^{\prime} \mathrm{E}$ and $35^{\circ} 55^{\prime} \mathrm{E}$. The country is about $900 \mathrm{~km}$ long and $80-161 \mathrm{~km}$ wide, with a total area of $118,484 \mathrm{~km}^{2}$ (11.8 million ha), of which $80 \%$ is land. The remaining $20 \%$ is covered by water, mainly comprising Lake Malawi, which is about $586 \mathrm{~km}$ long and $16-80 \mathrm{~km}$ wide. The rest of the water area is made up of the following lakes: Lake Chilwa, Lake Malombe and Lake Chiuta and there are also rivers a majority of them flowing into Lake Malawi. The country is divided into three administrative regions namely Northern Region, Central Region and Southern Region with population distribution, population density and energy resources as shown in Table $\mathbf{1}$.

Malawi is one of the poorest countries in the world (in the bottom 10\%) with gross domestic product based on purchasing-power-parity (PPP) per capita GDP of about USD 900 in 2010 [1]. GDP composition by sector is $35.5 \%$ agriculture, $19.9 \%$ industry and $44.6 \%$ services. The population of Malawi is currently about 15 million and recently, it has been increasing at a rate of about $2.8 \%$ per annum. About $83 \%$ of the population lives in rural areas and about $75 \%$ of the population carries out

${ }^{*}$ Corresponding author. farming as smallholders on fragmented customary land [2]. Crops that contribute significantly to the economy of the country are tobacco, tea, sugarcane and cotton with these crops accounting for about $75 \%$ of total exports for the country and tobacco alone contributing about 52\%. Urban growth is increasing at a rate of about $6.7 \%$, of this $60 \%-70 \%$ live in traditional housing areas and unplanned settlement areas. Poor planning has resulted in extreme urban squalor and deprivation, poor sanitation, and the rapid spread of communicable waterborne diseases. Improper disposal of wastes, agro-chemicals (fertilizers and pesticides) and effluent from industries, hospitals and other institutions are major urban problems with only $77 \%$ of proper disposed waste and most of the waste water enters the river systems that provide drinking water for downstream communities as raw sewerage. There is little environmental impact from mining and industries due to the minor economic contribution from these sectors. There is an increase in extraction of construction materials like sand and clay for bricks (with a high demand for fuel wood for curing of the bricks), lime for cement and quarry stones for concrete. Sand and gravel extraction leave large holes, which provide breeding environments for disease vectors and waterborne pathogens. Another important mining industry activity is making of cement, which is the second greatest contributor 
Table 1. Malawi population, land area and energy resources by region in 2008 (adapted from Malawi biomass strategy, 2009).

\begin{tabular}{|c|c|c|c|c|}
\hline & Northern Region & Central Region & Southern Region & National \\
\hline Rural population ('000) & 1343 & 4814 & 5147 & 11,304 \\
\hline Total population ('000) & 1594 & 5773 & 6263 & 13,630 \\
\hline Land area (sq. km) & 27,200 & 35,600 & 31,200 & 94,000 \\
\hline Population density (people/ha) & 0.59 & 1.62 & 2.01 & 1.45 \\
\hline Available energy resources & $\begin{array}{l}\text { Biomass, coal, hydro, } \\
\text { uranium }\end{array}$ & Biomass, hydro & $\begin{array}{l}\text { Biomass, coal, } \\
\text { hydro }\end{array}$ & $\begin{array}{l}\text { Biomass, coal, hydro, } \\
\text { uranium }\end{array}$ \\
\hline $\begin{array}{l}\text { Current electric generating capacity } \\
\text { (MW) and source by ESCOM }\end{array}$ & $\begin{array}{l}\text { 2.15-Diesel } \\
\text { 4.5-Hydro }\end{array}$ & - & $\begin{array}{l}\text { 15-Gas turbine } \\
\text { 279.3-Hydro }\end{array}$ & $\begin{array}{l}\text { 2.15-Diesel 15-Gas } \\
\text { turbine 283.8-Hydro }\end{array}$ \\
\hline
\end{tabular}

to greenhouse gases in Malawi, after agricultural-related processes. The industry sector is a great contributor to creation of noise, dust, air pollution from furnaces and effluent by-products, however, these impacts are currently quite low.

\section{Economic Development}

Alleviation of poverty in Malawi has been a point of focus for government policies for over a decade. This endeavor has been spearheaded by two documents, namely the Malawi Poverty Reduction Strategy (MPRS, 2002) and the Malawi Growth and Development Strategy (MGDS, 2005). The MGDS has been built upon the foundations of MPRS and incorporated lessons that were learnt in the implementation of MPSR. MGDS recognizes that strong and sustainable economic growth is a key to poverty reduction and it focuses on:

- Agriculture and food security;

- Irrigation and water development;

- Transport infrastructure development;

- Energy generation and supply;

- Integrated rural development;

- Prevention and management of nutrition disorders and HIV/AIDS.

The first phase of MGDS was implemented between 2006 and 2011 and now it is being extended for another five years. In the MDGS under the energy generation and supply theme, Malawi is aiming to increase access to reliable electricity and reduce reliance on biomass fuels. Improving energy supply is clearly a vital input to the development of productive sectors of any country's development. There have been quite some challenges in focusing on the priority areas that have been set out in the MGDS in that it seems there is no order in which the priority areas are being addressed. As we are approaching the first phase of MGDS, food security has been attained but what remains is the sustainability aspect. The energy sector has been receiving some attention in doing feasibility studies for alternative energy supply sources but no course of action has been undertaken to implement long term plans for the sector. National budget allocation to the energy and mining sector has remained well below $1 \%$ of the total national budget for the past 15 years.

\section{Energy Situation}

One of the challenges the country faces is being able to meet the energy needs of the various sectors in the country. Energy supply deficiencies are common which result in interruptions to processes that require energy as an input. A prominent example is the national electrical energy system which is accessible to less than $1 \%$ of the rural population and is unreliable. From 2008 statistics, about $90 \%$ of Malawi's population use wood for fuel and charcoal production, accounting for about $88.5 \%$ of the country's energy requirements, $6.4 \%$ comes from petroleum, $2.8 \%$ from electricity and $2.4 \%$ from coal. Households account for $83 \%$ of all energy consumption, with industry taking $12 \%$, transport taking $4 \%$ and the service sector taking $1 \%$. Statistics show that $85.7 \%$ of the population use paraffin in hurricane and pressure lamps for lighting, 7.2\% use electricity, 2.2\% use candles, $2.6 \%$ use firewood and $1.4 \%$ use other means of alternatives for lighting. For cooking, $88 \%$ of the population use firewood, $8 \%$ use charcoal, $2 \%$ use electricity, $1 \%$ use paraffin and $1 \%$ use other means such as crop residues, animal dung and those not mentioned above [3]. Looking more closely at the various energy sources for lighting and cooking for both rural and urban areas gives us results as summarized in Table 2.

The Government of Malawi has embarked on quite a number of programs and projects to improve the standard of living for the rural masses which should be able to eventually result in energy utilization switch. Even with such programs being carried out, less than $1 \%$ of the rural population has access to electricity.

In 2004, four energy laws were created to help opera- 
tions in the energy sector in Malawi. These are four Energy Acts aimed at addressing various aspects of the energy sector which are: Act 20, the Energy Regulation Act which established Malawi Energy.

Regulatory Authority (MERA); Act 21, the Rural Electrification Act which laid the foundation for the formation of Rural Electrification Management Committee and Rural Electrification Fund; Act 22, the Electricity Act which deals with electricity issues in terms of licensing, tariffs, generation, transmission, distribution, sales contracts and related issues; Act 23, the Liquid Fuels and Gas (Production and Supply) Act which handles issues related to liquid fuels and gas production in terms of licensing, safety, pricing, taxation, strategic reserves and any other related issues. Following some surveys that were carried out, energy consumption by sector and by fuel type in 2008 was as summarized in Table $\mathbf{3}$.

Total energy produced in Malawi is less than energy that is consumed hence a need to import some energy products in form of oil products and coal. Figure 1 shows the trend of energy produced compared to energy consumed for Malawi over the past recent years.

It can be observed that the gap between energy produced and that consumed is increasing which translates into increasing energy imports.

It is common knowledge that as the environment de- grades, there are consequences that are observed in energy systems, whether it be the supply, transportation or utilization aspects. A simple example of rural communities depending on biomass as their main source of energy will face energy challenges because of deforestation. For Malawi which relies mainly on hydro power generation, there has been a growing impact of power generation from environmental degradation. Population growth and the pressures associated with it have resulted in most of the hills being laid bare in most of the catchment areas of the rivers. People have been opening up gardens in areas previously protected and use a lot of fertilizers to compensate for low yields and in addition the use of firewood and charcoal both as a household energy source and for business has depleted the forests. This has resulted in more soils being prone to erosion. When raining, a lot of soils are eroded into the river tributaries and later to the Shire River, which is the biggest river in Malawi and where electrical generation is mainly being done. The soils being eroded are full of nutrients from the use of artificial fertilizers and so when these soils and their nutrients are deposited into the river they provide necessary nutrients to the aquatic plants and they then grow and multiply [4]. Also the soil being eroded into the river cause problems at the intakes of the water which goes into the power stations.

Table 2. Population distribution by source of energy for lighting and cooking (source: Malawi census main report, 2009).

\begin{tabular}{|c|c|c|c|c|c|c|}
\hline \multirow{2}{*}{ Source of energy } & \multicolumn{3}{|c|}{ Cooking (\% of population) } & \multicolumn{3}{|c|}{ Lighting (\% of population) } \\
\hline & National & Rural & Urban & National & Rural & Urban \\
\hline Charcoal & 8 & 1.7 & 43.4 & 0 & 0 & 0 \\
\hline Electricity & 2 & 0.4 & 13.6 & 7.2 & 1.9 & 37.5 \\
\hline Firewood & 88 & 95.7 & 41.8 & 2.6 & 2.9 & 0.4 \\
\hline Gas & 0 & 0 & 0.1 & 0 & 0 & 0 \\
\hline Paraffin & 1 & 1.2 & 0.7 & 85.7 & 92.5 & 46.5 \\
\hline Others & 1 & 1 & 0.5 & 1.3 & 1.6 & 0.3 \\
\hline Candles & 0 & 0 & 0 & 3.2 & 1.1 & 15.3 \\
\hline
\end{tabular}

Table 3. Total energy demand by sector by fuel in Malawi in 2008 (source: national biomass energy strategy document, 2009).

\begin{tabular}{|c|c|c|c|c|c|}
\hline \multirow{2}{*}{ Sector } & \multicolumn{5}{|c|}{ Energy demand by fuel type (TJ) } \\
\hline & Biomass & Coal & Electricity & Petroleum & Total (\% of total) \\
\hline Household & 127,574 & 5 & 1798 & 672 & $130,049(83.2 \%)$ \\
\hline Industry & 10,004 & 3481 & 2010 & 3130 & $18,625(11.9 \%)$ \\
\hline Transport & 270 & 15 & 35 & 5640 & $5960(3.8 \%)$ \\
\hline Service & 452 & 174 & 477 & 558 & $1661(1.1 \%)$ \\
\hline Total (\% of total) & $138,300(88.5 \%)$ & $3675(2.4 \%)$ & 4320 (2.8\%) & $10,000(6.4 \%)$ & 156,295 (100\%) \\
\hline
\end{tabular}




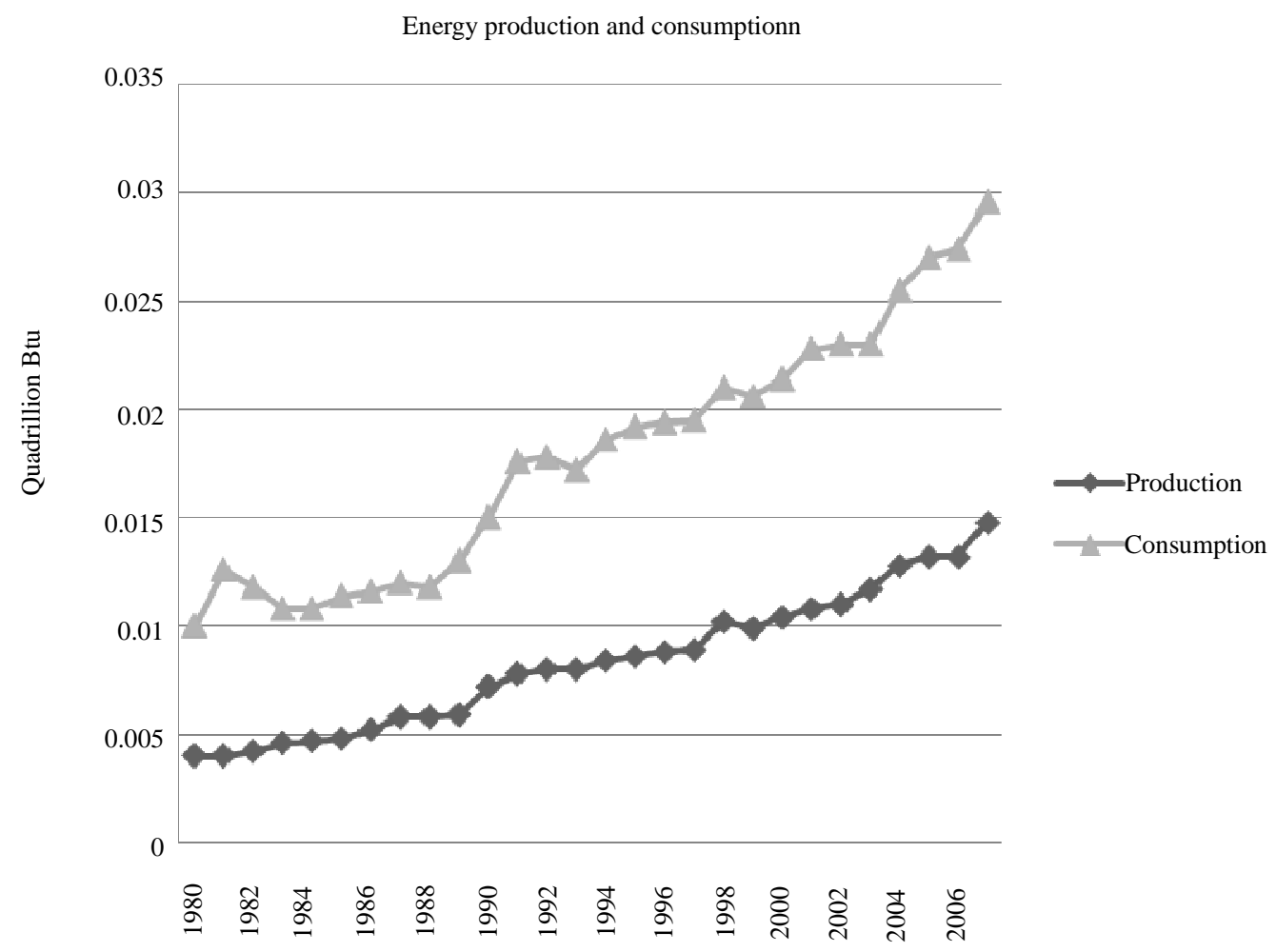

Figure 1. A graph showing energy produced and energy consumed (adapted from IAEA international energy statistics).

\section{Energy Development}

The energy sector in Malawi has not been able to meet all the energy requirements across the other sectors and this has been a major challenge for some time and has considerably contributed to the slow development of the various sectors in the country. Many studies that have been done have already shown that a correlation exists between energy and economic development, with various aspects of developmental trends being exposed depending on the area of study. At household level, it has been observed that total energy use increases with income. Commercial energy intensity follows a different path in that at low levels of economic development, commercial energy use is negligible which means that commercial energy intensity approaches zero. When there is economic development, industry booms and commercial energy intensities increase as well [5]. Similar patterns are evident in other economic activities linked to natural resources utilization such as local air pollution. It has also been established from studies in a number of countries that economic prosperity leads to more energy consumption [6,7]. Also income growth is associated with an increasing trend to use modern energy services. Since it has been observed that energy consumption increases with economic prosperity, it means that rising GDP is generally accompanied by increased energy consumption per capita [8]. The increasing trend in energy consump- tion with increasing economy is decreasing in the recent times because of improved efficiencies and utilization of modern energy technologies. Generally total primary energy use rises with income but the two do not change in lockstep. At early stages of economic development, the dominance of inefficient fuels and technologies results in large inputs of energy but as economic development proceeds and more modern, efficient fuels and technologies are adopted, energy intensity input per unit of economic output begins to decline. The general downward trend in energy intensity may be interrupted as a country enters the first stages of industrialization and materialintensive manufacturing becomes the dominant economic driver [9].

Elements of achieving national energy security are included in other government's key policy and strategy documents such as the Vision 2020, the Millennium Development Goals and the National Energy Policy. There is a need for periodic policy and strategic reviews to ensure realization of energy sufficiency for the country. One of the major challenges facing the energy sector is the financial allocation (a negligible fraction of the national budget) that is not in line with the global energy trends and this has to change if any meaningful progress is to be made in achieving the government's agenda in improving energy supply. The financial spending figures for Malawi between 1996 and 2010 show that Energy 
and Mining Services sector had the highest allocation of the total national budget in 2010 which was $0.53 \%$ [10]. If this trend continues, development of the energy sector will remain a major challenge since the private sector is not playing a major role in the activities of this sector. The National Energy Policy being the framework for the development of the energy sector in Malawi sets out policy goals, objectives, strategies and priority actions. The policy also sets out target energy mix for the future as shown in Table 4 aimed at achieving a shift from an energy sector that heavily relies on biomass to one that better distribution among the various energy sources in the country.

Objectives of Malawi's energy policy are:

- To improve efficiency and effectiveness of commercial energy supply industries;

- To improve the security and reliability of energy supply systems;

- To increase access to affordable and modern energy services;

- To stimulate economic development and rural transformation for poverty reduction;

- To improve energy sector governance;

- To mitigate environmental, safety and health impacts of energy production and utilization.

In fulfilling the above objectives, the energy policy enacted in 2003 aims to achieve three long term goals which are:

- Make the energy sector robust and efficient, to support government's agenda of poverty reduction, sustainable economic development consequently enhancing labor productivity;

- Catalyze the establishment of a more liberalized, private sector-driven energy supply industry;

- Transform the country's energy economy from one that is overly dependent on biomass to one with a high modern energy mix [11].

Looking at Table 4, it is clear that the targets are far from being met using the current approaches in developing

Table 4. Energy mix, projections and targets as in national energy policy.

\begin{tabular}{cccccc}
\hline $\begin{array}{c}\text { Energy } \\
\text { source }\end{array}$ & $\begin{array}{c}\mathbf{2 0 0 0} \\
\text { (Actual) }\end{array}$ & $\begin{array}{c}\mathbf{2 0 0 8} \\
\text { (Actual) }\end{array}$ & $\mathbf{2 0 1 0}$ & $\mathbf{2 0 2 0}$ & $\mathbf{2 0 5 0}$ \\
\hline Biomass & 93.0 & 88.5 & 75.0 & 50.0 & 30.0 \\
Coal & 1.0 & 2.3 & 4.0 & 6.0 & 6.0 \\
Electricity & 2.3 & 2.8 & 10.0 & 30.0 & 40.0 \\
Liquid fuels & 3.5 & 6.0 & 5.5 & 7.0 & 10.0 \\
Nuclear & 0.0 & 0.0 & 0.0 & 0.0 & 4.0 \\
Renewable & 0.2 & 0.4 & 5.5 & 7.0 & 10.0 \\
TOTAL (\%) & $\mathbf{1 0 0 . 0}$ & $\mathbf{1 0 0 . 0}$ & $\mathbf{1 0 0 . 0}$ & $\mathbf{1 0 0 . 0}$ & $\mathbf{1 0 0 . 0}$ \\
\hline
\end{tabular}

the energy sector and this is having serious impacts on the economy of the country. The energy sector is still in the infancy stage where energy consumption is relatively low with inefficient energy conversion methods being dominant.

The energy supply sector comprises five key components namely electricity, liquid fuels and gas, coal, biomass and other renewable sources of energy. There have been a number of programs and projects that have been implemented with the intention of achieving the already mentioned goals but there has been little progress so far. A closer look at the components of the energy supply sector brings to light the following.

\subsection{Electricity Supply}

This sector generates electricity mainly from hydro potential but thermal (mainly diesel and gas based) and small photovoltaic systems are also in use. A significant number of commercial and industrial enterprises have installed their own diesel and petrol operated generators due to unreliable energy supply from the national energy supply utility company, but it is still a challenge to determine the capacity of such due to gaps in regulations. Electricity Supply Corporation of Malawi (ESCOM) Limited is the only electrical power supplier and it is a publicly owned company which was established by an Act of Parliament in 1957 which was revised in 1963 and then 1998. The total installed capacity of ESCOM is about $302 \mathrm{MW}$, of which $94 \%$ is generated by hydropower and the remaining $6 \%$ is thermal. Almost all the ESCOM's hydro generation stations are located in the Southern region of Malawi along Shire River (the main outlet of Lake Malawi) except for a capacity of $4.5 \mathrm{MW}$ which is located in the Northern region on Wovwe River. Electrical power is transmitted to all other parts of the country through $132 \mathrm{kV}$ network with $66 \mathrm{kV}$ being used as well in other areas. Distribution network is at $33 \mathrm{kV}, 11 \mathrm{kV}$ and 400/230 V. Overall, the electricity network is not in very good condition, resulting in substantial losses on the transmission and distribution networks of about 18\% $22 \%$ of the generated electrical energy. One of the important forms of energy is that plays a key role in a country's development is good supply of electrical energy. Table 5 shows the current installed electricity capacity from various hydro power stations in Malawi being operated by ESCOM; however, available capacity at most of the times is generally about $80 \%$ or less of the installed capacity [12].

Malawi has got more potential for generating electricity using hydro potential as evidenced by the outcome of some feasibility studies on various rivers in the country. The following are potential sites and the expected range of power and energy outputs: 
Table 5. Hydro electric power generation installed capacity by ESCOM (information from ESCOM).

\begin{tabular}{cccc}
\hline Year & Site & Capacity (MW) & $\begin{array}{c}\text { Cumulative } \\
\text { capacity (MW) }\end{array}$ \\
\hline 1966 & Nkula A & 24 & 24 \\
1973 & Tedzani I & 20 & 44 \\
1977 & Tedzani II & 20 & 64 \\
1980 & Nkula B & 60 & 124 \\
1986 & Nkula B & 20 & 144 \\
1992 & Nkula B & 20 & 164 \\
1995 & Wovwe & 4.5 & 168.5 \\
1996 & Tedzani III & 51.3 & 219.8 \\
2000 & Kapichira I & 64 & 283.8 \\
\hline
\end{tabular}

Manolo with a potential output of 60 to $130 \mathrm{MW}$, Henga valley with a potential output of 20 to $40 \mathrm{MW}$, Rumphi with a potential capacity of 3 to $13 \mathrm{MW}$, Chizuma with a potential capacity of 25 to $50 \mathrm{MW}$, Chasombo with a potential capacity of 25 to $50 \mathrm{MW}$, Malenga with a potential capacity of 30 to $60 \mathrm{MW}$, Mbongozi with a potential capacity of 25 to $50 \mathrm{MW}$, Kholombizo with a potential capacity of 140 to $280 \mathrm{MW}$, Mpatamanga with a potential capacity of 135 to $300 \mathrm{MW}$, Low Fufu with a potential capacity of 75 to 140 MW, Low Fufu and Tran with a potential capacity of 90 to 180 MW, High Fufu with a potential capacity of 90 to 175 MW, Chimgonda with a potential capacity of 20 to 50 MW and Zoa Falls with a potential capacity of 20 to 45 MW [13].

It is a known fact that electrical energy is one of the most preferred forms of energy because of a number of advantages among which are ease of transformation into other forms, it is easy transport, it is easy to change to the required voltage and it is relatively cheap to produce. Looking at the trend portrayed in Table 5, it can be observed that the cumulative generation capacity is growing quite slowly and not conducive to national development's requirements. The current suppressed demand for electrical power is currently at about $350 \mathrm{MW}$ and is projected to $600 \mathrm{MW}$ in 2015, $1200 \mathrm{MW}$ in 2025 and $1600 \mathrm{MW}$ in 2030. If the generation capacity growth trend continues the way it has been doing in the past, demand will continue being more than the supply capacity for some years to come. There are plans in what is called the Malawi Electricity Investment Plan to bridge the gap between demand and supply so that demand will be equal to supply by 2016 and thereafter, the demand will be less than supply. This can only be possible if there is action commitment from the government and development partners and not just paper commitment. The current electricity power supply in Malawi is quite unreliable and according to recent estimates, Malawi loses about USD 16 million annually due to power outages. Investing by the private sector in electricity generation remains a challenge due to the government subsidy provided to ESCOM in electricity generation which gives unfair advantage to ESCOM over any would be investors hence ESCOM has remained the sole electricity generation company to date. Capacity of privately owned generators is difficult to ascertain but according to a survey that was done by National Electricity Council in 2001, it was estimated that the capacity of private generators was 51.3 MW, but there are no later figures. Malawi has got a small electricity supply system as compared to her neighbors which are 2483 MW for Mozambique, 1186 MW for Tanzania and 1737 MW for Zambia (all are installed capacities as of 2008) [14]. In addition to local resources, there are plans to connect Malawi to the Southern African Power Pool in the next few years. The Malawi Rural Electrification Project (MAREP) was also established to increase the number of rural trading centers that have access to the national electricity grid and is now in its fifth phase. Electricity from photovoltaic modules is still insignificant when looking at the overall picture, but it is increasing in utilization, finding applications in telecommunications, lighting, refrigeration and water pumping.

A study was done to determine the correlation between electricity consumption and GDP for Malawi from data between 1970 and 1999 extracted from the statistical bulletins and economic reports published by the National Economic Council and the National Statistical Office. Ganger-causality (GC) and error correction model (ECM) were used to examine causality between $\mathrm{kWh}$ and GDP. The results showed that there was a bi-directional causality between kWh and GDP using GC and one-way causality running from GDP to kWh using ECM [15]. In conclusion the author wrote that ECM results reflect better the Malawi economy that of being less dependent on electricity since the economy is heavily dominated by the agricultural sector. However, this might not be an ultimate conclusion since the agricultural sector also depends on electricity although to a small extent in as far as Malawi is concerned because the agriculture sector does not use electricity mainly because of its absence in most of the rural areas where agricultural activities are concentrated. It can be argued that the agricultural activities can be having more electrical energy input if the electricity can be available because this can promote agricultural processing activities which in turn can have an impact in the overall economy of the country. Inadequate electrical power supply has been identified as one of the constraints affecting private sector development in Malawi. 


\subsection{Liquid Fuels and Gas Supply}

In the Energy policy document, the government of Malawi recognized the two main parts of this sector which are the upstream and the downstream. Upstream covers aspects of exploration of oil and gas, production and refinement of crude oil, ethanol and other fuels. Downstream encompasses supply logistics and marketing of liquid fuel products and gas. Some past studies showed that certain thick sedimentary rocks which may have hydrocarbon accumulations are present beneath the northern part of Lake Malawi and in the lower Shire Valley. In July 2011, two companies (Surestream Petroleum Limited and Simkara) were given licenses to carry out oil explorations in Lake Malawi. An extensive Strategic Environmental Assessment will be carried out prior to undertaking any work and the assessment will be presented to Ministry of Natural Resources, Energy and Environment for approval before exploration data acquisition commences. There are also efforts to promote oil and gas exploration ventures in Southern African Development Community (SADC) as a whole and this is through the SADC Energy Activity Plan. Malawi has no refineries for petroleum products because it has been proven to be uneconomical due to the small national market. Malawi therefore imports about $97 \%$ of its refined petroleum products; the balance is contributed by locally-produced ethanol which is sold directly to the oil companies for blending with petrol on a maximum 20:80 ratio of ethanol-petrol. In practice, the mixing ratio is usually 12:88 because ethanol production is inadequate and also because there is no legislation to make the blending mandatory resulting some petrol being unblended. Petroleum products are imported into the country mainly through three routes namely Dar Corridor, Nacala Corridor and Beira Corridor. The internal storage capacity of oil for the country to avert supply disruptions by natural or manmade emergencies is supposed to be 30 days but this is not the case on ground due to a number of economical and logistical challenges. The transport sector relies heavily on the oil imported supply; conse- quently its pricing is heavily influenced by trends on the international oil market.

\subsection{Biomass Supply}

The availability of biomass energy in Malawi can be made sustainable which currently it is not. Wood resource base is diminishing mainly because woodlands and trees in agricultural areas are being cleared up to start new farming land. Statistics show that between 1991 and 2008 about 669,000 hectares of woodlands were converted to farmland [16]. Diminishing standing stock is leading into gradual reduction of biomass that can be harvested. From the information already given, Malawi is heavily dependent on biomass fuels yet the national energy policy has little information on biomass energy supply. Looking at the biomass side of energy supply, a similar situation exists to that of electricity generation in that very little is being done to address issues concerned with improving the supply and efficiency of biomass, although it is the major energy source for the country. Household sector consumes about 92\% of biomass energy and the rest is distributed among the other sectors as shown in Table 6. About $76 \%$ of firewood is used for cooking, $21.5 \%$ for heating water, $2 \%$ for space heating and the remainder for other uses.

The national energy policy is focused on shifting energy use away from the current heavy reliance on traditional biomass to modern sources of energy like electricity, liquid fuels and renewable sources but little progress has been achieved so far. High dependence on biomass means that it should be a priority to find means and ways of improving utilization of energy from biomass alongside the issues of fuel switching. There are some policy contradictions that exist concerning this sector that continue to hinder progress for biomass fuel supply. Agricultural activities are diminishing resources for the supply of biomass in that as the population is increasing, more land is converted from forests to farming land. Although there are regulations to safeguard the affected forests, there are no mechanisms to ensure that the regulations

Table 6. Consumption of biomass energy by sector and fuel type in 2008 (adapted from national biomass energy strategy document, 2009).

\begin{tabular}{|c|c|c|c|c|}
\hline \multirow{2}{*}{ Sector } & \multicolumn{4}{|c|}{ Type of biomass energy (TJ) } \\
\hline & Charcoal & Firewood and sawdust & Residues (crop and wood) & Total \\
\hline Household & 8703 & 115,879 & 2992 & $127,574(92.2 \%)$ \\
\hline Industry & 31 & 4092 & 5562 & $9685(7 \%)$ \\
\hline Transport & 0 & 0 & 589 & $589(0.43 \%)$ \\
\hline Service & 102 & 350 & 0 & $452(0.33 \%)$ \\
\hline Total & $8836(6.4 \%)$ & $120,321(87 \%)$ & 9143 (6.6\%) & $138,300(100 \%)$ \\
\hline
\end{tabular}


are adhered to. Another example is that of charcoal in which its production from indigenous trees is deemed illegal unless it can be proven that it has been produced from a sustainably managed forest for which a production license has been applied for and received (article 81 of the Forestry Act, 1997). Charcoal is therefore continually being confiscated by government authorities yet nearly $40 \%$ of the urban households use charcoal for cooking [17]. Existence of such contradictions in various sectors hinders investments or efforts towards modernization in more sustainable alternatives of biomass fuels production. Another challenge is existence of different aspects of the biomass sector under different government departments. The supply side of biomass energy supply is covered under the National Forest Policy (1997), the Forestry Act (1997) and the Land Policy Act (2002) while general issues of energy supply fall under the Energy Policy (2003). While the energy policy envisages an ambitious transition from wood fuels to electricity, liquid fuels, coal and renewable energies, little is written concerning modernization, development or sustainability of the wood fuel sector [18]. To fill this gap a Biomass Energy Strategy was formulated and the document was produced in 2009. This strategy makes a pro-active approach towards managing and developing the biomass energy sector instead of just tolerating biomass fuels as an interim solution while waiting for alternative energy supply sources (which has been the case for some time). The Forest Policy recognizes the importance of wood fuels for livelihood of producers in the rural areas and promotes sustainable wood fuel production [19]. The total consumption of biomass in 2008 was estimated at about 9 million tons of wood equivalent. Rural households accounted for about $80 \%$ of total consumption while urban households consumed about $12.2 \%$ and the remainder was distributed among the remaining sectors as already shown in Table 6.

Malawi has a potential to produce bio-fuels for its local markets which can result in reduction of fuel importation bill. This can be accomplished by blending biofuels with petrol or diesel as the case has been of blending ethanol and petrol which has been done for over 25 years. There are two ethanol plants in Malawi, one in Salima and another one in Chikhwawa both plants being connected to sugar factories. Apart from blending with petrol, ethanol has also been converted to gel and liquid fuels for both domestic and industrial use but on a small scale because the products have been deemed not economically viable or not suited to the local cooking practices. The country is capable of producing different nonfood feed-stocks by converting unutilized land for biofuels crop production. Malawi needs to take the necessary steps to manage risks associated with bio-fuels crop production and increase opportunities for bio-fuel devel- opment through locally-suited but regionally and internationally aligned good practices in bio-energy production. Malawi's focus should be on emerging trade and investment opportunities for the country, implications for poverty reduction, supply-side constraints to expanding production, use and trade in bio-fuels and promotion of new investment mechanisms.

In the field of biomass and biogas, the country has favorable conditions for the application of a majority of technologies in these fields. So far there have been some initiatives for improved wood cook stoves both at domestic and institutional levels. Biogas digesters have been constructed in a number of areas as pilot projects for the rural communities with variable success levels but uptake of the technology remains a challenge to date. In an attempt to minimize the use of biomass fuels and provide the communities in rural and urban areas with alternative source of energy, the government undertook a number of initiatives. Some of these are: the program for biomass energy conservation (ProBEC) which seeks to use more energy efficient technologies like improved stoves; introducing more efficient firewood management through drying and splitting wood among other ways; improved kitchen management through better ventilation at the cooking place, at domestic and institutional levels and use of alternative renewable energy sources such as solar and gel fuel [20]. Another one is the Promotion of Alternative Energy Sources Project (PAESP) which seeks to promote non-traditional fuels for cooking and heating to reduce effects of environmental degradation.

\subsection{Coal Supply}

The estimated coal reserves in Malawi are between 80 million tons and 1 billion tons of which 20 million tons are proven reserves of bituminous type. Quality of the coal varies with energy values ranging from 17 to 29 $\mathrm{MJ} / \mathrm{kg}$. There are four coal fields in Malawi, three in the northern region and one in the southern region. Three are in Karonga and Rumphi districts while the fourth one is at Ngachira in Chikhwawa district in the Lower Shire Valley. Coal mining started in 1985 and currently two fields are being mined in Rumphi district. The coal produced from these sites is not enough to suffice the country's industrial needs consequently the balance is imported from Mozambique. Coal is used in various industries for heating but is not generally used as a domestic energy supply such that it can be concluded that its use in households is negligible. There are plans by the government of Malawi to start generating electricity from coal and feasibility studies are still being carried out.

\subsection{Other Renewable Energy Sources}

Malawi is endowed with a number of renewable energy 
resources yet utilization of these resources is still in infancy stages. In the field of solar, quite high levels of solar energy in the range of $1200 \mathrm{~W} / \mathrm{m}^{2}$ in the warm months and $900 \mathrm{~W} / \mathrm{m}^{2}$ in the cool months are received in most parts of the country which would enable photovoltaic systems and solar thermal systems to perform well. For wind energy systems, there are quite a good number of areas in the country with mean wind speeds above 5 meters per second almost throughout the year. There have been other programs and projects which promoted the use of renewable energy technologies in Malawi. In terms of bio-fuels, there are some crops that are known to have substantial amounts of oil in their seeds which are still being investigated for use in blending with conventional fuels that are in use today. Malawi lies along the Great Rift Valley and therefore traces of geo-thermal reservoirs have been said to exist. Technologies that use solar energy have a high potential of being implemented successfully since solar energy is a resource that is available in abundance throughout the country. This would be very important for most of the rural areas that are unable to access energy from the national electricity grid which is a common form of energy for various humans needs including water treatment which is a very essential element in healthy livelihood. There have been a number of initiatives in the renewable energy sources sector with the notable ones being the National Sustainable and Renewable Energy Program (NSREP, 1999), Barrier Removal to Renewable Energy in Malawi (BARREM, 1999), Program for Biomass Energy Conservation (ProBEC, 2002) and the Promotion of Alternative Energy Sources Project (PAESP).

\subsection{Nuclear Supply}

Malawi has about 63,000 tons of proven reserves of uranium at Kayerekera in Karonga district and another deposit which is yet to be quantified at Illomba in Chitipa district. Mining of uranium started in 2008 at Kayerekera but currently all the uranium that is mined is exported. Energy that is currently being used in mining of uranium is not supplied from the national electricity grid due to the site being located in a remote area as well as the supply itself being unreliable. Electrical generators operating on diesel are used for electrical power supply to the mining site. There are plans by the government to build a nuclear power station in the far future.

\section{Conclusion}

The energy sector in Malawi is still in the early stages of development as evidenced by the heavy utilization of biomass to meet a high proportion of the country's energy demand. The targeted energy mixes as set out in the national energy policy are far from being met and there- fore there is a need for change of approach by formulating new energy development strategies altogether. Energy supply remains a great challenge for Malawi to date especially for people living in rural areas. There has been lack of direction and commitment in addressing issues in the energy sector to such an extent that at certain times when the energy sector is mentioned, it actually means the electricity sector and a proof of this noted through some official government literature in which the words energy and electricity are used interchangeably. The Malawi situation is a sure example that availability of energy resources does not automatically translate into production of energy from the available resources. Lack of financial commitment, lack of favorable conditions for investment in the energy sector, lack of political will and poverty are among the major factors that have contributed to underdevelopment in the energy sector for Malawi. The energy sector will continue being what it is unless deliberate steps are taken to prioritize the sector which will result in better political will, allocation of more funds from the national budget to the sector, mobilization of resources and putting in place some incentives for the private sector to actively participate.

\section{REFERENCES}

[1] World Bank, "World Development Indicators,” The World Bank, Washington DC, 2011.

[2] Malawi Government, "State of the Environment Report," Ministry of Natural Resources, Energy and Environment, Lilongwe, 2010.

[3] Malawi Government, “Census Main Report,” National Statistical Office, Zomba, 2009.

[4] W. W. Liabunya, "Malawi Aquatic Weeds Management at Hydro Power Plants,” ESCOM Ltd., Generation Business Unit, Blantyre, 2004.

[5] R. A. Judson, R. Schmelensee and T. M. Stoker, "Economic Development and the Structure of the Demand for Commercial Energy,” The Energy Journal, Vol. 20, No. 2, 2004, pp. 29-57.

[6] B. R. Mitchell, "International Historical Statistics: The Americas 1750-1993,” 4th Edition, Stockton Press, New York, 2004.

[7] A. Maddison, "The World Economy: A Millennial Perspective," Development Centre of the Organization for Economic Co-Operation and Development, Paris, 2004.

[8] IEA Key World Energy Statistics, 2004. http://www.iea.org/publications

[9] A. Grübler, “Transitions in Energy Use,” Encyclopedia of Energy, Vol. 6, 2004, pp. 163-177.

[10] Publications, Statistical Yearbook, 2010. http://www.nso.malawi.net/data_on_line.html

[11] Malawi Government, “National Energy Policy,” Department of Energy Affairs, Lilongwe, 2003.

[12] Escom \& Electricity, Power Generation. 
http://www.escom.mw

[13] Malawi Government, "Malawi Electricity Investment Plan," Ministry of Natural Resources, Energy and Environment, Lilongwe, 2010.

[14] SAPP Statistics, 2010. http://www.sapp.co.zw/

[15] C. B. L. Jumbe, “Co-Integration and Causality between Electricity Consumption and GDP: Empirical Evidence from Malawi,” Energy Economics, Vol. 26, No. 1, 2004, pp. 61-68. doi:10.1016/S0140-9883(03)00058-6

[16] Malawi Government, "Malawi Biomass Energy Strategy,”
Ministry of Natural Resources, Energy and Environment, Lilongwe, 2009.

[17] Malawi Government, "Forestry Act," Department of Forestry, Lilongwe, 1997.

[18] Environment, 2010. http://www.sdnp.org.mw

[19] Malawi Government, “National Forest Policy,” Department of Forestry, Lilongwe, 1996.

[20] M. Owen and J. Saka, "The Gel Fuel Experience in Malawi,” Evaluation for GTZ ProBEC and Malawi Department of Energy Affairs, Lilongwe, 1996. 